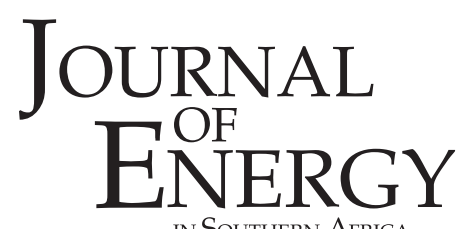

IN SOUTHERN AFrica

\title{
Scoping exercise to determine load profile archetype reference shapes for solar co-generation models in isolated off-grid rural African villages
}

\author{
Gerro Prinsloo, a, ${ }^{\mathrm{a}}$ Robert Dobson, ${ }^{\mathrm{a}}$ Alan Brent ${ }^{\mathrm{b}}$ \\ a Department of Mechanical and Mechatronic Engineering, Stellenbosch University, Private Bag X1, Matieland \\ 7602, South Africa \\ b Centre for Renewable and Sustainable Energy Studies, School of Public Leadership, Stellenbosch University, \\ Private Bag X1, Matieland 7602, South Africa
}

\begin{abstract}
For many off-grid rural communities, renewable energy resources may be the only viable option for household and village energy supply and electrification. This is especially true for many rural regions in southern Africa, where the population spread is characterised by small villages. These rural villages rely heavily on firewood, charcoal, biochar, biogas and biomass to meet thermal energy needs (hot water and cooking), while candles, kerosene and paraffin are mostly used for lighting. Alternative energy systems such as hybrid concentrated solar micro-CHP (combined heat and power) technology systems have been proposed as viable energy solutions. This paper reports on a scoping exercise to determine realistic hourly reference profile shapes for thermal and power energy consumption in isolated rural African villages. The results offer realistic energy consumption load profiles for a typical rural African village in time-series format. These reference load profiles enable experimental comparison between computermodelled solar micro-CHP systems and control automation solutions in isolated rural village micro-grid simulations.
\end{abstract}

Keywords: smart village; community microgrids; discrete time simulation; off-grid demand response; disaggregated load profile; sustainable energy

Journal of Energy in Southern Africa 27(3): 11-27

DOI: http://dx.doi.org/10.17159/2413-3051/2016/v27i3a1375

* Corresponding author

Tel: +27 218084376 Email: gerroprinsloo@sun.ac.za 


\section{Introduction}

Limited grid infrastructure to certain sparsely populated parts of Africa still deprives many rural Africans of access to the basic energy requirements. Figures from the International Energy Agency (IEA) show that around $59 \%$ of the total African population do not have access to electricity (IEA, 2014). To improve living standards in remote parts of Africa, research towards rural electrification and the provision of clean green energy to isolated domestic rural settlements are essential (Dagbjartsson et al., 2007).

A framework for rural renewable energy provision has shown that energisation options, based on hybrid renewable energy systems and resources, may be the only viable option for rural village energy supply and electrification (Kruger, 2007). This is true for many off-grid rural communities in Africa, where the nature of the population spread has resulted in small isolated villages. Such rural settlements call for smart energy management in standalone decentralised off-grid renewable energy systems (Mulaudzi and Qase, 2008), and zero-netenergy based $100 \%$ renewable energy systems in community-shared solar power solution configurations (Lund, 2015).

Standalone concentrating solar micro combined heat and power (micro-CHP) technology has been identified as a potential solution to meet energy demands in isolated off-grid rural areas (Barbieri et al., 2012; Prinsloo \& Dobson, 2015). In order to simplify the development of control automation solutions for micro-CHP systems, dynamic modelling approaches have been followed to simulate these systems (Cho et al., 2007). These parametric model representations are then used in control approaches (i.e. Model Predictive Control), to mathematically optimise the micro-CHP system operation and energy balance through energy storage and intelligent dispatch algorithms in a multifamily homestead or family micro-grid environment (Lund, 2015; Cho et al., 2008).

Realistic hourly energy consumption profiles for heat and electricity are required to validate and compare mathematical and computer simulation models for storage and control automation solutions in cyber-physical micro-CHP model representations (i.e. TRNSYS, Homer, EnergyPlus, EnergyPlan, ReEds, REopt) (Ho, 2008). Currently, it is difficult to find time-series datasets that represent load profiles for thermal and electrical power consumption in a rural African village context. Thermodynamic modelling and optimisation can be improved when realistic reference profile shapes (archetypes) are available. These profiles can be used as a benchmark in the evaluation and comparison of computer simulation and system control models for new locally relevant village-scale autonomous solar Stirling micro-CHP systems, such as the community solar system currently under development at Stellenbosch University (Prinsloo \& Dobson, 2015).

Big Data (large datasets, in this case containing information on user energy consumption) and energy informatics research offer smart-meter (a device that can record and communicate user electricity consumption) datasets to study hourly domestic household energy usage patterns. The recorded datasets are used to develop residential load profiles (OpenEI, 2015). These load profiles have proven to be immensely valuable in optimising intelligent power systems, particularly when developing optimisation strategies in deep learning and demand response algorithms (Cho et al., 2008). In modern co-generation and micro-grid optimisation research, micro-grid and Smartgrid user demand data can be processed to determine standardised hourly load profile shapes as archetypes for various types of energy users (Shilts \& Fischer, 2014). These datasets are further valuable in load forecasting, daily demand response analysis, storage scheduling optimisation and resource coordination strategies in smart micro-grid ecosystems (Deloitte, 2011; OpenEI, 2015). Smart-meter datasets are almost exclusively available for electricity usage in grid-connected urban applications, making it difficult to statistically determine realistic thermal or electrical load profile patterns for prospective new installations in rural Africa.

This paper presents a load profiling and scoping exercise based on available literature on thermal and electrical power consumption patterns in small rural African villages (Cross \& Gaunt, 2003; Heunis \& Dekenah, 2014; Meyer, 2000; Muya, 1996; OpenEI, 2015; Tinarwo, 2009; Sprei, 2002). The results of the study offer basic geometric archetypal energy reference shapes for hourly heat and electric load profiles. These load profiles will be incorporated in simulation software, and used in conjunction with computer models representing combined heat and power as well as distribution automation for remote rural electric power systems. These demand profiles will allow researchers to evaluate the performance of the modelled generation system in remote rural and islanded community microgrid configurations for deregulated micro-markets, based on statistical tariff price data, generation capacity, energy storage capacity, weather data, and user load profiles.

\section{The traditional rural African village energy context}

The South African government has committed itself to provide basic free electricity to its citizens, based on a favourable low-income social residential energy tariff structure (DME, 2003). In certain parts of Africa and southern Africa, however, the land topography and mountainous terrain have, over the years, caused people to spread out and to live 
on the habitable parts of the hilltops and ridges. In this context, families often live in these isolated homestead clusters and typically stay in round/square indigenous huts with thatched grasstop roofs. This pattern of development makes it important to research the determinants of electricity demand for potential newly electrified low-income rural African village households.

Many of these traditional rural African villages rely on a combination of biomass and fossil-fuel sources to meet their day-to-day energy requirements (i.e. candles, biomass, firewood, paraffin) (Mulaudzi \& Qase, 2008; Lloyd, 2014). Surveys have also found that fuelwood is often the main source of energy for cooking and heating, while paraffin and candles are mainly used for lighting (Masekoameng, 2005; Reddy, 2008). Specific data for the African country of Malawi is shown in Table 1 . The data shows an overwhelmingly high percentage of fuelwood consumption relative to the other sources of energy (Makungwa et al., 2013). This is especially true in the case of the rural population, where most of the rural communities are traditionally dependent on subsistence farming. Table 1 shows that fuelwood accounts for $89 \%$ of energy consumed by households in Malawi; in fact, solid biomass such as fuelwood is the primary source of energy used in cooking in many self-sufficient African homes.

The map of Africa in Figure 1 shows the population percentage in African countries that use solid fuels (fuelwood, charcoal, coal, crop waste, and dung) as the primary cooking fuel, especially in rural areas (WHO, 2010). This is further supported by the IEA's Africa Energy Outlook report (IEA, 2014), which offers a breakdown of the cooking fuel type per African region in Figure 2. The statistical bars for rural Africa on the right-hand side of the figure confirm that a large portion of rural Africa relies mostly on fuelwood and other forms of solid biomass for cooking. It also emphasises the fact that African governments have not yet been able to energise rural areas, to the extent that electricity is

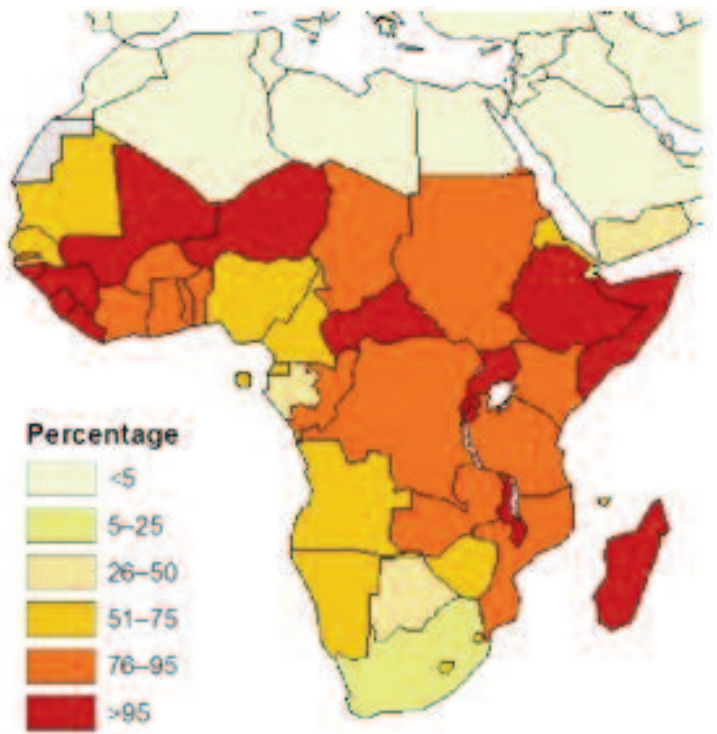

Figure 1: Percentage of households in Africa using solid fuels such as fuelwood as the primary cooking fuel (WHO, 2010).

recognised as a basic right or basic service as force for development (DME, 2003). Figure 2 shows that rural people in sub-Saharan Africa, with South Africa being the exception, rely heavily on fuelwood for their day to day energy needs.

The situation in the rural areas of South Africa is little different. A survey conducted in three rural villages in the area around Giyani, Limpopo Province, for example, showed fuelwood to be the main source of energy for heating and cooking, while candles and paraffin provided indoor and outdoor lighting (Masekoameng, 2005). Another study looked at domestic energy use in recently electrified low-income households in a fairly remote area in the Eastern Cape Province (Africa et al., 2008) and reported that, despite electrification, a large portion of the rural community still used (non-forest type) fuels to meet much of their energy requirements, particularly cooking, boiling water and space heating. It is typical for communities in rural areas that gain access to electricity to keep using more tradi-

Table 1: Energy share and variations in African household cooking fuel type for rural and non-rural areas in Malawi, figures in terra-joules per year (TJ/y) (IEA, 2014).

\begin{tabular}{lcccc}
\hline \multicolumn{1}{c}{ Fuel type } & Rural & Urban & National & \% \\
\hline Fuelwood & 105320 & 10560 & 115880 & 89.1 \\
\hline Charcoal & 2360 & 6340 & 8700 & 6.7 \\
\hline Crop residue & 2980 & 11 & 2991 & 2.3 \\
\hline Electricity & 0 & 1798 & 1798 & 1.4 \\
\hline Paraffin & 240 & 430 & 670 & 0.5 \\
\hline Coal & 0 & 5 & 5 & 0.0 \\
\hline LPG gas & 0 & 2 & 2 & 0.0 \\
\hline Total & 110970 & 19076 & 130046 & 100 \\
\hline
\end{tabular}




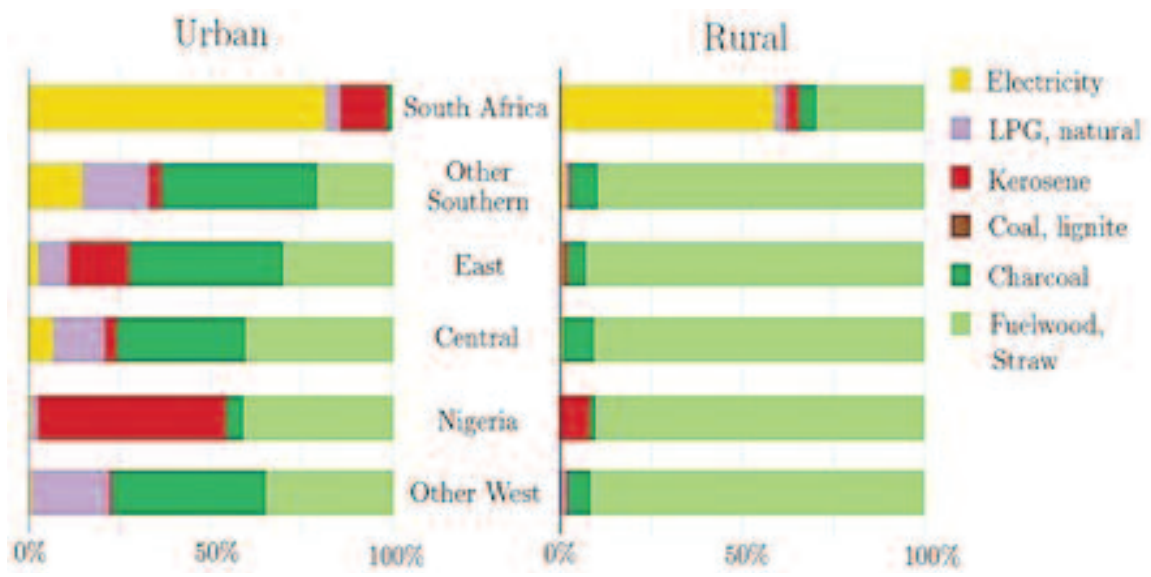

Figure 2: Energy share and variations in household cooking fuel type for rural and non-rural areas in African regions (IEA, 2014).

tional fuels (such as wood) for such thermal related activities. Another investigation in the Eastern Cape Province, into the use of household fuelwood in small electrified towns in the Makana District, found that more than two-thirds of rural households still used fuelwood (despite wood carrying burdens and transportation discomforts). The consistent opinion in this region had favoured fuelwood, as it was said that wood provided good heat and was available to be collected cheaply, while it helped saved electricity costs (Shackleton et al., 2007). The study further provides interesting figures on the territorial use of energy, the annual demand and direct-use value of fuelwood; the volume/weight of wood collected; amounts used for cooking and boiling hot water per household; the collection trip duration; drought impact and shortages; collection frequencies and perceptions around the ease of collection (Shackleton et al., 2007).

Fuelwood deficits are becoming an increasing problem in rural parts of Africa, adding to the wood collection burden on rural households. In many parts of Africa, households are highly vulnerable to the rapidly degrading forest resources (Palmer \& MacGregor, 2008). The reason is that fuelwood is collected primarily from natural wood-land and shrub-land, which are non-forest-type sustainable sources (Aron et al., 1991). A study in Ethiopia shows that rural households in forest-degraded areas increase their labour input for collection in response to a shortage in fuelwood (Damte et al., 2012). A Namibian study on fuelwood scarcity also confirmed more labour going into wood collection rather than reduced energy consumption (Palmer \& MacGregor, 2008). These studies found limited evidence for energy substitution away from fuelwood to other energy sources, despite the declining availability of forest and non-forest stocks. It shows that sheer determination and the Ubuntu culture helped Africans learn to cope with fuelwood scarcity. Interesting in Table 2 is the gender-disaggregated household responses to changes in firewood availability and time allocated to collect energy resources for rural Ethiopia (Scheurlen, 2015).

From a solar co-generation energy supply and village demand profiling point of view, the data from these studies is valuable in a bottom-up load profiling exercise, especially in an environment where fuelwood and other traditional fuels. The information from studies cited is also useful in anticipating the potential energy demand and shape of the daily load profile for any potential co-generation system solution that may be installed as prosumer-based systems (cooperative, self-generation or self-supply). The profiles are also required in grid-edge utility or municipal power supply systems for isolated rural villages in Africa. A survey conducted by Lloyd and Cowan (2004) in an informal settlement in South Africa further provides important information on average daily and monthly household electricity consumption. A summary of this survey, presented in Table 3 , shows that the average monthly energy consumption level for rural households cooking without electricity is $150 \mathrm{kWh}$, while for those cooking with electricity is $210 \mathrm{kWh}$ (Lloyd \& Cowan, 2004). An average monthly ener-

Table 2: Average numbers of hours per week spent to fetch fuelwood in African rural areas (United Nations Development Programme, 2011).

\begin{tabular}{lcccc}
\hline \multicolumn{1}{c}{ Subjects } & Guinea & Madagascar & Malawi & Sierra Leone \\
\hline Women & 5.7 & 4.7 & 9.1 & 7.3 \\
\hline Men & 2.3 & 4.1 & 1.1 & 4.5 \\
\hline Girls & 4.1 & 5.1 & 4.3 & 7.7 \\
\hline Boys & 4.0 & 4.7 & 1.4 & 7.1 \\
\hline
\end{tabular}


Table 3: Monthly use of electricity and paraffin at homesteads in Khayelitsha (Lloyd \& Cowan, 2004).

\begin{tabular}{|l|c|c|c|}
\hline \multicolumn{1}{|c|}{ Homestead type } & & Paraffin & Electricity \\
\hline & Sampled & Median & Median \\
\hline Households cooking with electricity & 124 & 6 litres & $210 \mathrm{kWh}$ \\
\hline Households not cooking with electricity & 102 & 18 litres & $150 \mathrm{kWh}$ \\
\hline
\end{tabular}

gy consumption level of $150 \mathrm{kWh}$ per rural household equates to approximately $0.484 \mathrm{kWh}$ per day. This information can help to define a realistic reference archetype energy profile for a rural African homestead once the load shape has been defined.

Another finding from Lloyd and Cowan's study (2004) is that many houses with access to electricity also use paraffin for cooking, corroborating the findings of other studies showing that a significant percentage of newly electrified households continue to also use alternative fuels (iShack, 2013). Approximately $68 \%$ of Khayelitsha households with a regular metered supply of electricity use electric stoves as the main cooking appliance and the rest typically use paraffin stoves. Among non-electrified households, it was found that $92 \%$ used paraffin stoves as the main cooking appliance and the rest mainly used LPG.

\section{Rural African village hourly load profiles}

Since renewable energy can act as socio-economic catalyst, this section focuses on electricity supply to isolated rural villages from a smart village perspective. It describes the load profile or hourly schedule of energy use (electrical and thermal) anticipated for rural households in Africa from an energy management system perspective. This load profile analysis uses both quantitative and qualitative information on energy use patterns by non-electrified and electrified rural households. Sample load profiles are typically presented as hourly or sub-hourly time graphs that show the variation in energy consumption over the duration of a full day.

In general, a two-dimensional load profile represents the relative timing in the demand versus the amount of energy used for each time increment. Of particular interest is the time factor of the load profiles, while less emphasis is placed on variation in magnitude between the different studies. The information presented in this section will assist with the emulation of realistic rural electrical and thermal load profiles to be used in solar combined heat and power microgrid simulations.

In this part of the profile scoping exercise, the interest is more on the timing of the energy usage pattern for the energy consumption curve than on the comparative energy load amplitude levels. With this in mind, it becomes interesting to compare the basic geometric shapes and general trends in the load profiles for rural and agriculture-based homesteads in Africa.

\subsection{Rural electrical energy usage profile shapes}

It is difficult to locate hourly-based time-series datasets on electrical power consumption in isolated rural African homes since existing smart-meter instrumentation datasets are almost exclusively available for electricity usage in grid-connected urban applications. This is one reason why the present scoping exercise was initiated, to locate whatever data is available on energy consumption for remote rural areas and to be able to match these patterns to hybrid renewable energy based microproduction of electricity. It further allows researchers to see how this data can contribute towards compiling a reference archetypal remote rural load profile that represent the behavioural patterns and social practices around the energy usage culture in Africa.

In this respect, consider two hourly-based electrical load profiles for single rural village households measured in two different African countries. Figure 3 shows the averaged single household load profiles for rural villages in Zimbabwe and Uganda (Tinarwo, 2009; Sprei, 2002). The load profiles in both these studies were obtained from physical measurements taken in rural African settlements. The measured load profiles for the two sets of rural households (Figure 3) are both broadly characterised by an energy peak in the morning followed by a slightly larger energy peak in the late afternoon and evening. The geometric shape of these load profiles are typical for domestic energy systems, where occupants mainly use electricity when at home during the morning and evening (Shilts \& Fischer, 2014). A study concerning microgrid design for rural African villages made use of load profiles that are remarkably similar to those in Figure 3 (Bokanga \& Kahn, 2014).

In the data logger-based measurements, taken at a small farming community in Zimbabwe in Figure 3 (a), a smaller third load peak of electricity usage is visible around noon. This mid-day peak which appears briefly before fading away and can probably be attributed to farmworkers returning home during their lunch hour. This behaviour is typical for a farming village where people work in close proximity to their homes. For the energy consumption 


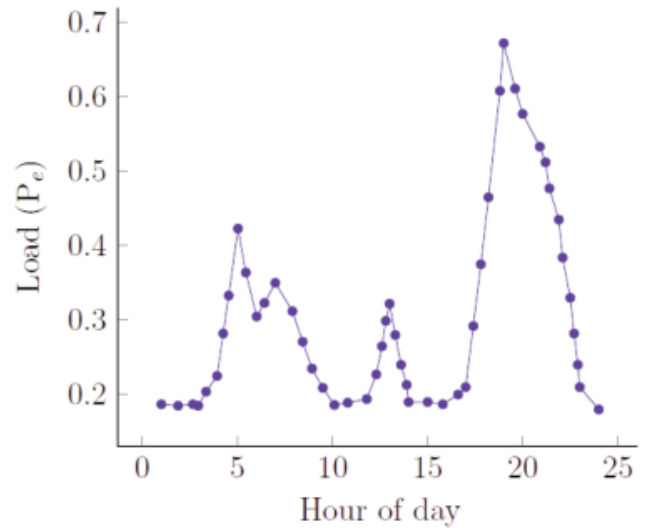

(a)

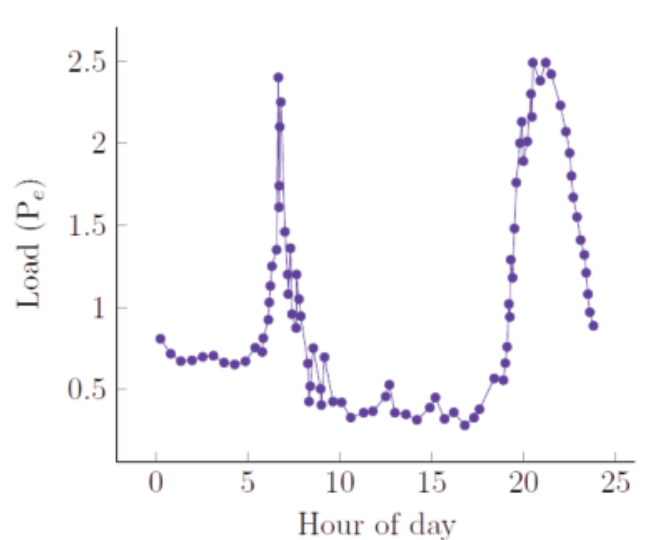

(b)

Figure 3: Average household load profiles, in kW, measured at rural villages at (a) Zimbabwe and (b) Uganda (Tinarwo, 2009; Sprei, 2002).

pattern in Figure 3(b), measurements were taken directly on the distribution transformer of a rural village microgrid power system in a semi-agricultural setting (Sprei, 2002). These measurements were taken with a load metering system with a finer time resolution, explaining the sharper peaks in the load profile representation.

What is important to note in this load profile shape in Figure 3(b) is the relatively smaller energy consumption peak in the load profile around noon. In this case, the smaller mid-day peak in the load profile may be indicative of the behaviour for the semi-farming community where not all workers return home for lunchtime and use electricity. Apart from the mid-day peak in the load profiles, there seems to be a strong correlation in the measured energy usage patterns for the two independent rural load profile datasets from the two countries (two prominent peaks, morning and evening). The similarities suggest that the load profile shapes for different parts of Africa may be fairly uniform, showing a strong correlation with people being at home to use electricity. The morning peaks can be associated with people switching on lights, using kettles and making breakfast. The large peak in the evening results from people returning home and again switching on lights, cooking dinner, heating water for cleaning/bathing and use televisions.

Extending the scope beyond the African context, to literature on the international front, it is clear that the same load trends and profile shapes prevail in the rural load areas of non-African countries (Ketjoy, 2005; Nayar, 2014; Fall et al., 2007; Susanto, 2012). This is illustrated in Figure 4 where measured energy load profiles are presented for Ban Pang, Praratchatan, Thailand; a rural settlement in Western Australia; a small village in Alaminos, Philippines; the San Juanico, Mexico; rural households in Lao People's Democratic Republic and a load profile for a single family home in Puerto Plata, Dominican Republic (Ketjoy, 2005; Nayar, 2014; Fall et al., 2007). The spread of rural load profiles, in Figure 4, illustrates that the same daily energy pattern, measured for rural Africa, appears to hold true in rural households and small rural villages in other rural parts of the world. All include an energy peak in the morning, another around noon, and a large peak in the evening. A potential smaller (single) energy consumption peak around noon may represent customer presence and energy usage during lunchtime break.

Literature also describes a spread of rural energy load profiles that have been used in rural electrification computer simulation and modelling schemes (Yumoto, 2011; Casillas \& Kammen, 2012; Ohijeagbon \& Ajayi, 2014; Kenneth \& Tarilanyo, 2013). Most of these models represent a slightly coarser scale of measurement (depicting hourly load profile time-steps), but the same load shape appears in most of these other load profile models for rural Africa. Figure 5 shows the average hourly representative load profile shapes for models in rural areas of Uganda (HOMER defined model), Botswana, Nigeria, and the Niger Delta (Yumoto, 2011; Casillas \& Kammen, 2012; Ohijeagbon \& Ajayi, 2014; Kenneth \& Tarilanyo, 2013). These correlate with the trends observed in the measured load profiles for rural settlements in Zimbabwe and Uganda (Figure 3).

In a computer simulation study, Varma et al. (2015) proposed various rural community load profile models, based on household type in the State of Uttarakhand in India as part of a hybrid solar system evaluation experiment (Figure 6). The Uttarakhand region needs special consideration in terms of electrification as the population density in this region is quite low and more than half of the population lives in rural areas (Verma et al., 2015). As in Africa, many of the remote villages and communities in Uttarakhand do not always have access to affordable and clean energy as a result of the terrain and the general lack of infrastructure. The load profiles in Figure 6 show strong resemblances to the rural African load profiles in Figure 3. These profiles 


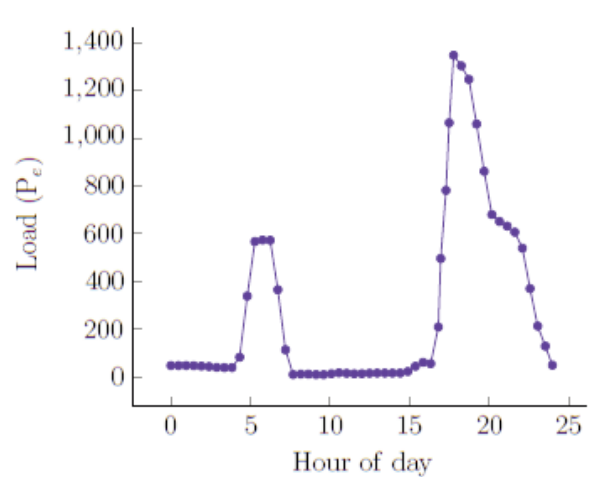

(a)

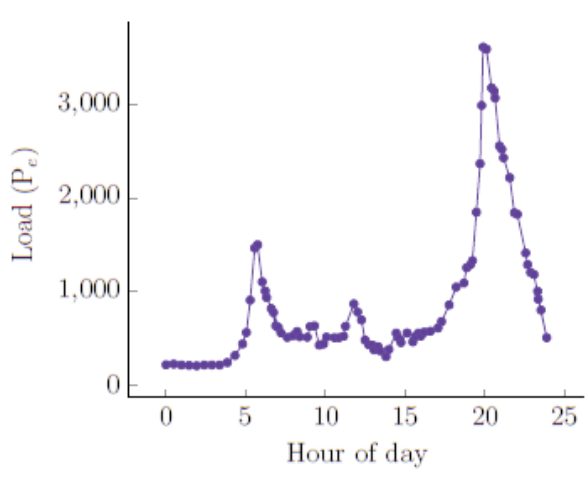

(c)

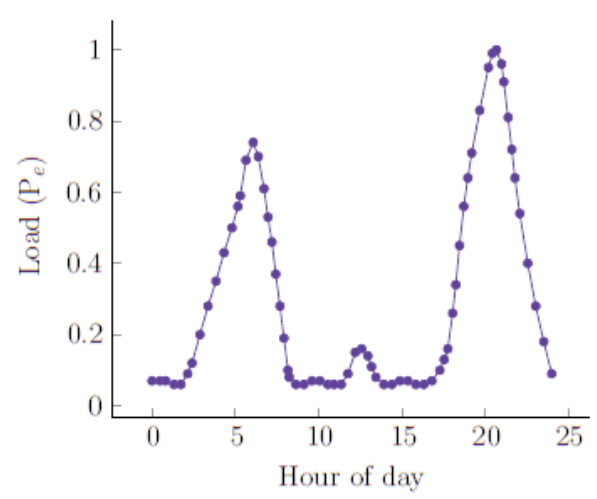

(e)

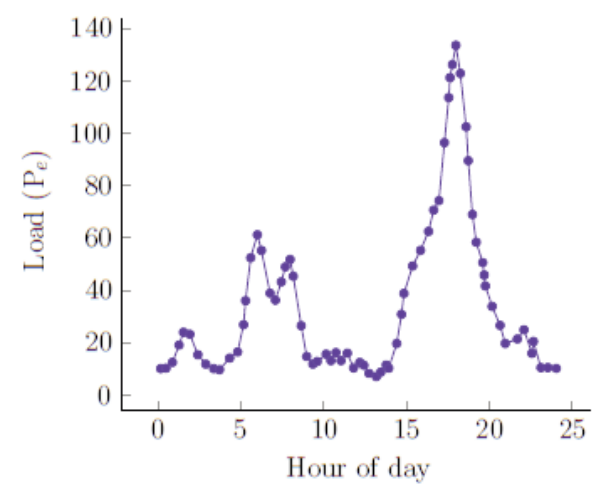

(b)

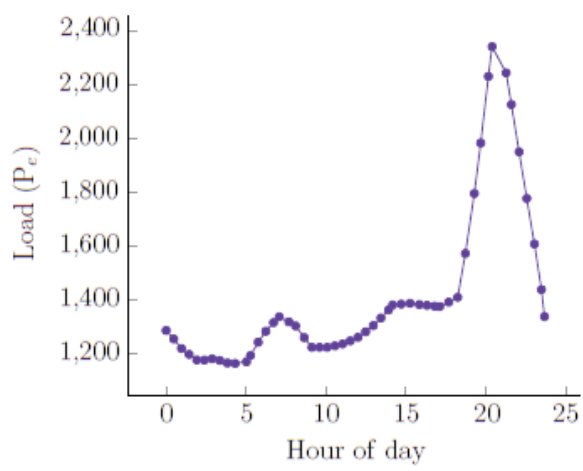

(d)

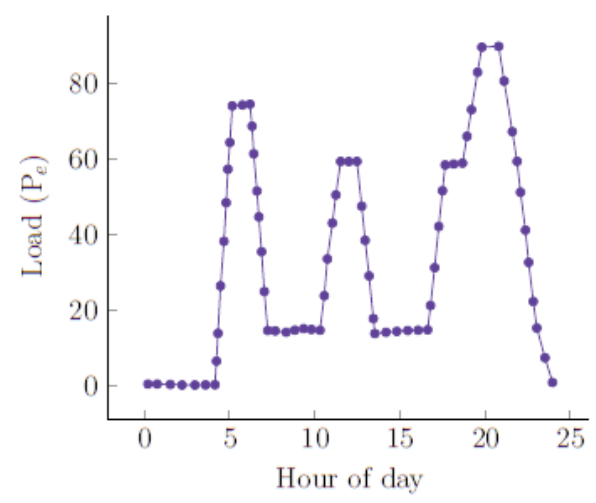

(f)

Figure 4: Energy load profiles for rural households and villages in various countries: (a) Ban Pang, Praratchatan, Thailand (Ketjoy, 2005); (b) Rural Western Australia (Nayar, 2014); (c) Alaminos, Rural Philippines (Fall et al., 2007); (d) San Juanico, Rural Mexico (Fall et al., 2007); (e) Rural Lao household, PDR (Susanto, 2012); and (f) Puerto Plata, Dominican Republic (Fall et al., 2007).

were chosen to represent actual rural household configurations in India and were used in experiments relating to energy access analysis and techno-financial evaluations. It shows similarities with the research of this paper where archetype load profiles for a typical rural villages are being formulated.

Research has also been conducted on a load profile prediction model for residential consumers in South Africa (Heunis \& Dekenah, 2014). This prediction model formed part of the development of an electrical distribution pre-electrification software tool (Figure 7). This powerline software planning tool and software architecture was developed in col- laboration with the electricity utility Eskom in South Africa, to serve as a standalone design parameter decision support system aimed at building, compiling and formulating energy load profiles prior to new grid electrification projects.

During the first phase of the development of this load prediction model and tool, measurements were taken from pre-paid meter systems and smart meters in newly electrified houses, in order to define new electrification energy datasets. These pay-asyou-go datasets were then used to find the average and standard deviation values in the domestic electricity consumption patterns for a typical new home or household, as shown in Figure 7(a). This infor- 


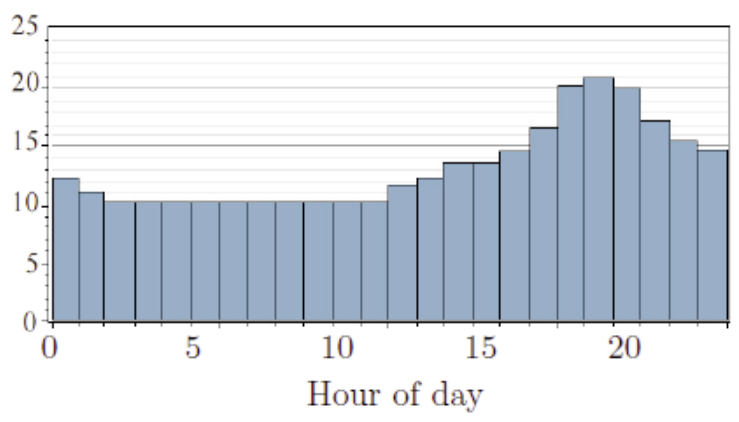

(b)

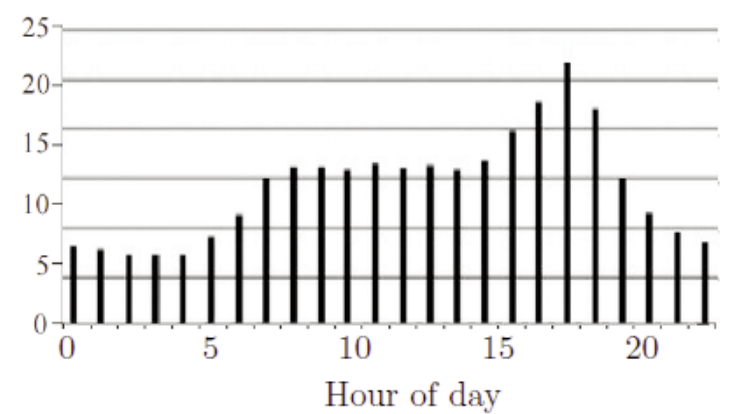

(b)

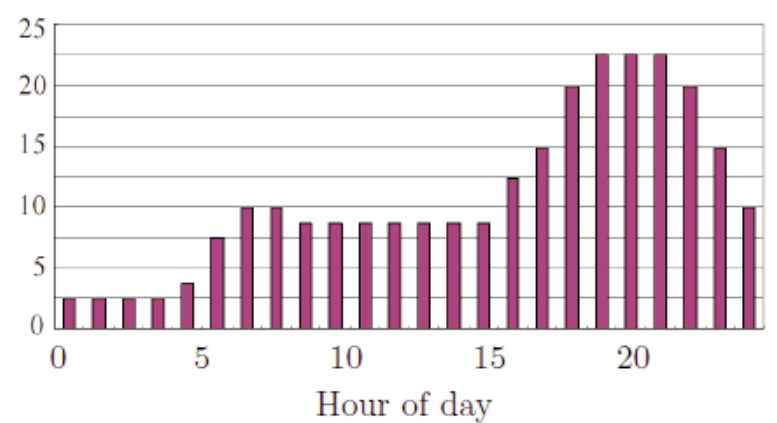

(b)

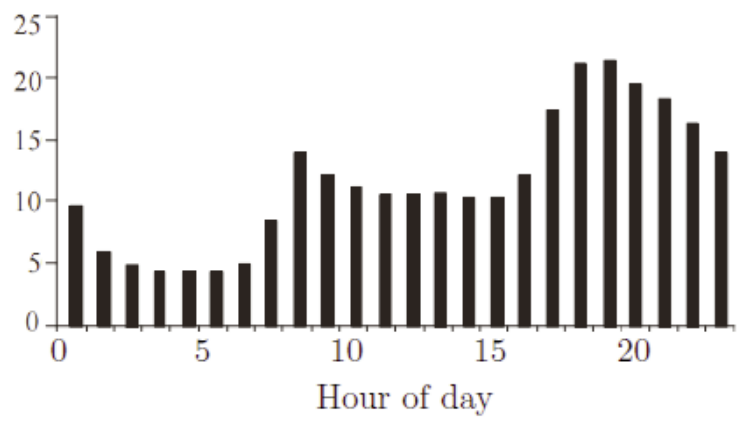

(b)

Figure 5: Computer models for selected daily rural energy load profiles for various African countries (a) Homer model, rural Africa (Casillas \& Kammen, 2012); (b) Botswana (Yumoto, 2011); (c) Sokoto, North-west Nigeria (Ohijeagbon \& Ajayi, 2014); and (d) Akassa, Niger Delta (Kenneth \& Tarilanyo, 2013).

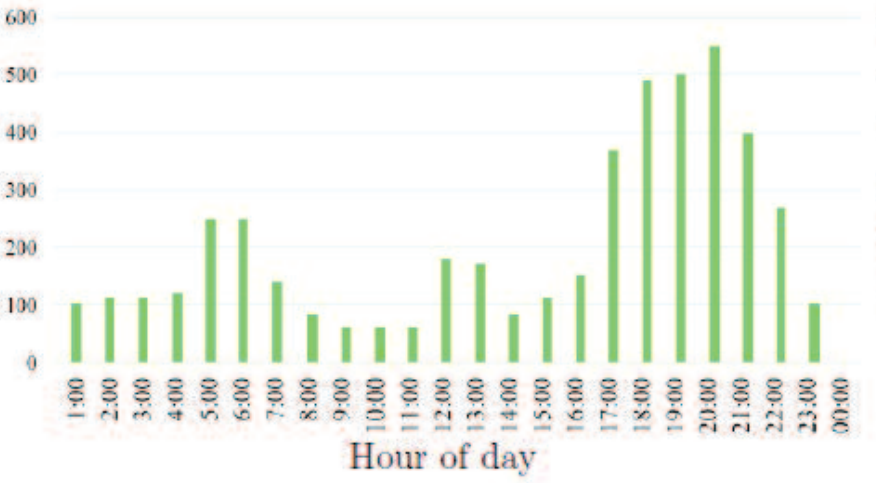

(a)

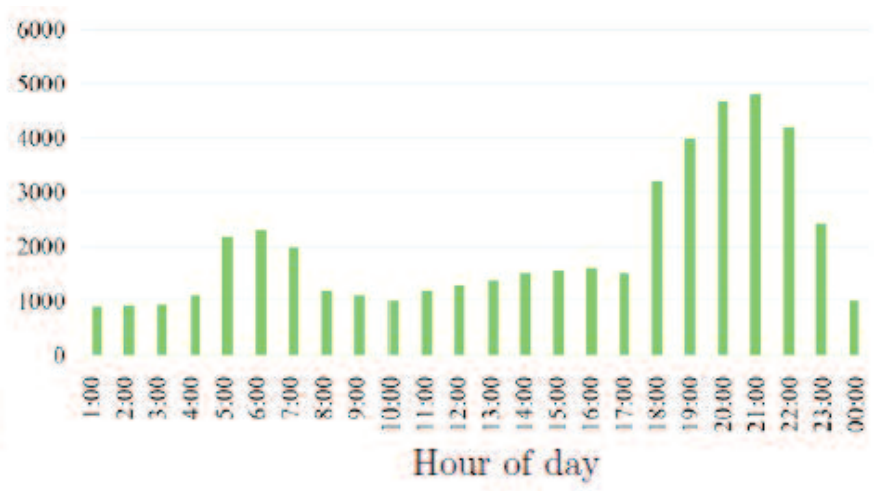

(b)

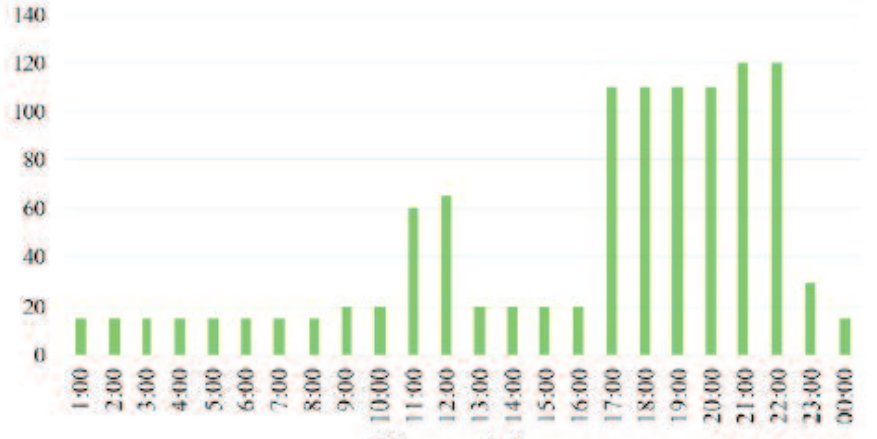

Hour of day

(c)

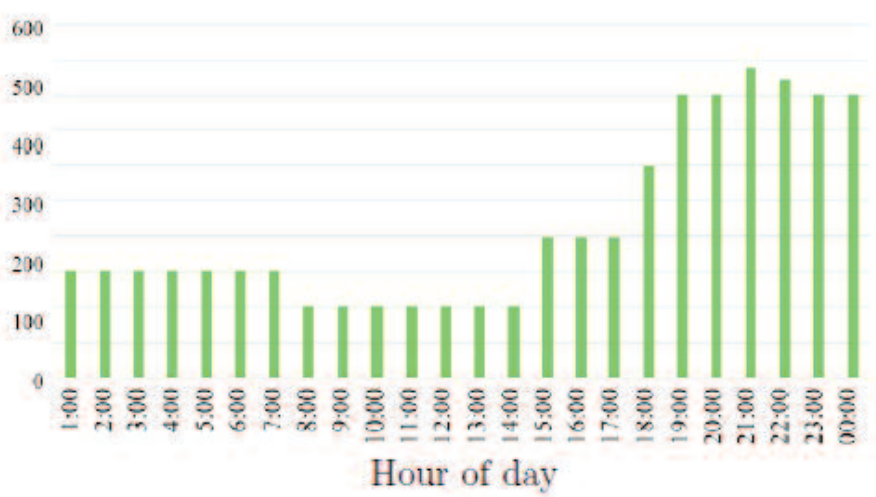

(d)

Figure 6: Daily average connected load for rural village scenarios in India. (a) Small village 5-6 small households; (b) Medium households, range of appliances; (c) Small standalone household; and (d) Small standalone off-grid rural household (Verma et al., 2015). 

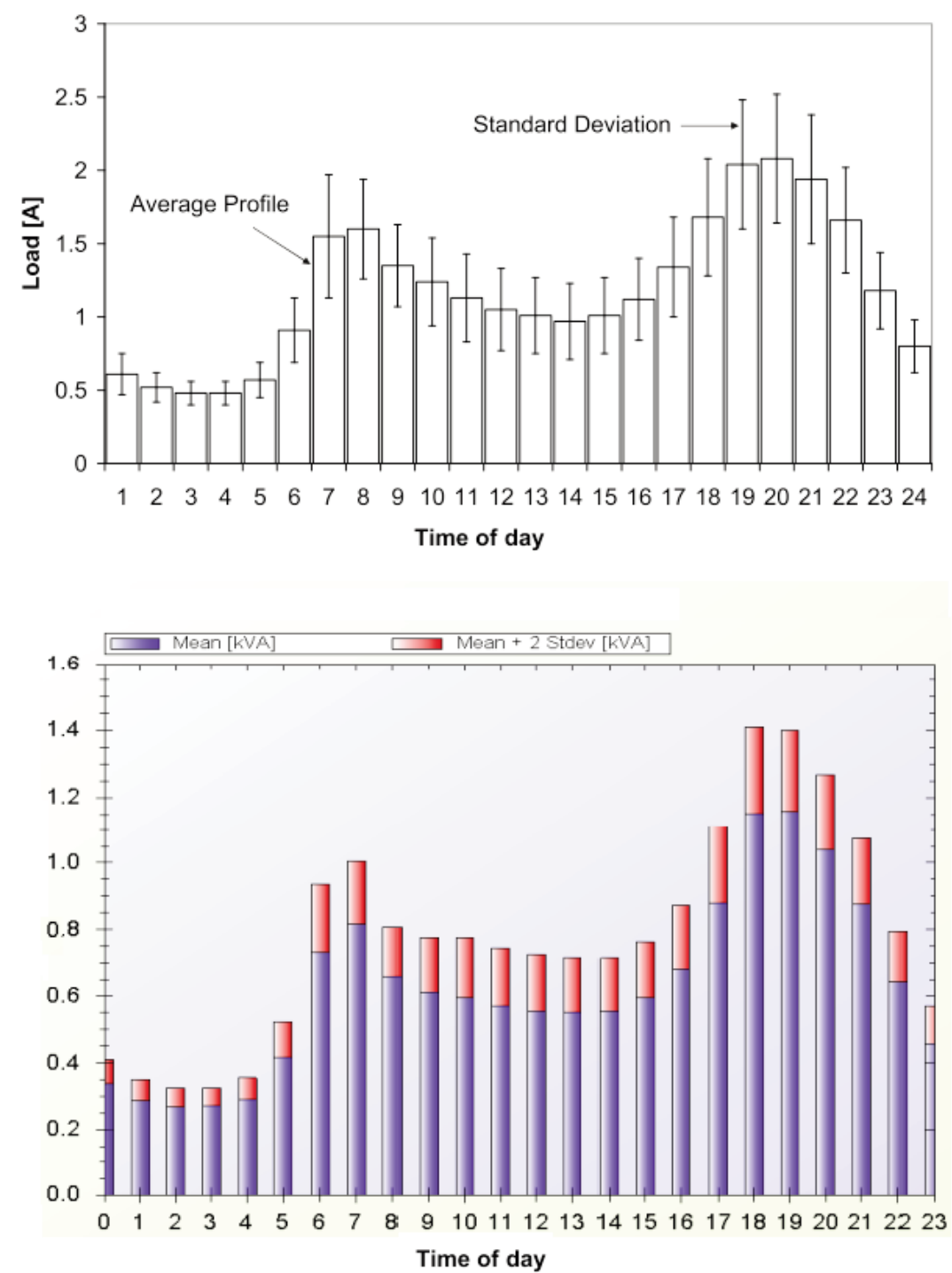

Figure 7: Load prediction with a grid distribution pre-electrification tool. (a) Average and standard deviation profiles; (b) Predicted energy profile and deviation (Heunis \& Dekenah, 2014).

mation was subsequently used in a prediction model and grid-planning strategy to compute probable domestic load curves for a group of new households, as shown in Figure 7(b). This prediction model and tool was developed to help anticipate consumption levels in newly planned electrical grids as well as in planning distribution retrofits for grid power network infrastructure extensions to new village zones and small towns.

By nature of the demand side load modelling technique, the load characteristics and electricity consumption patterns in Figure 7 represent profiles for newly planned homes in grid-connected township areas, where newly built homes are often fitted with electrical water heaters. These, and the addition of other appliances that would not typically be present in off-grid households, may explain the mid-day variations in the daily energy consumption profiles when comparing urban housing load profiles to the load profile shapes for rural village homes as shown earlier in Figure 3.

\subsection{Rural thermal energy profile shapes}

The consumption load profiles for thermal energy, like electrical energy, are also presented on a twodimensional chart that shows the instantaneous thermal or electrical load in kilowatts over 24 hours. This again offers a convenient way to visualise geometrical profiles for thermal energy usage patterns and to observe dynamic timing variations in the thermal load requirements, while making it easy to study the temporal load variations and changes. Since the current research focus is on water-cooled micro-CHP systems, the interest in thermal energy in this paper is largely biased toward rural hot water usage. In an electrified rural environment, hot water usage makes up, on average, $30-50 \%$ of total energy usage (Harris et al., 2008).

As with the electrical energy profiling exercise, it was found that very little data was available on hot water usage in rural African village settlements. Electronic datasets on hot water draw-off patterns for off-grid isolated rural areas are virtually non- 


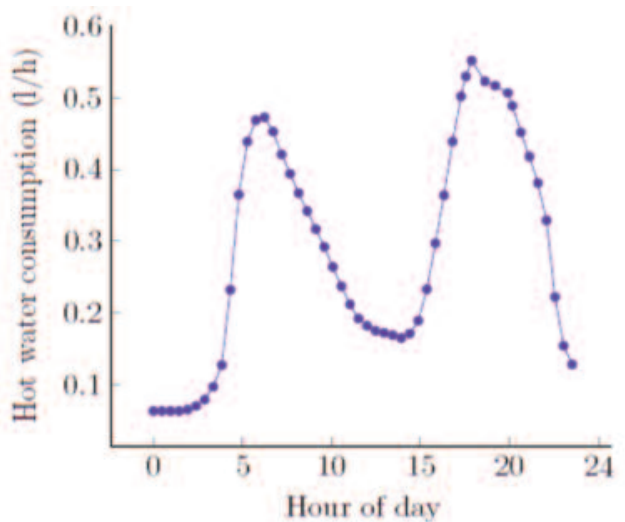

Figure 8: Per capita hourly hot-water consumption for a traditional rural South African household (Meyer, 2000; Muya, 1996).

existent. This means that one has to rely on information obtained in a scoping exercise to obtain pattern templates to use in computer modelling and simulation experiments. Research has been conducted on hot water consumption in rural households in Southern Africa since the early 1990s. Two studies, in particular, present a unique view on the energy context in Southern Africa and provide valuable information on hot water usage patterns based on elaborative surveys (Meyer, 2000; Muya, 1996). The results obtained once-again show the double- peak demand shape, as illustrated in Figure 8.

As with the electrical energy profile patterns described earlier in this paper, the hot-water drawoff pattern in Figure 8 shows strong correlation with human activities and household behavioural patterns (place profile-based). The bulk of hot water consumption is also concentrated in the morning and the evening. In a traditional agricultural homestead, most family members would wash and clean in the afternoon and evening, making the peak load for hot water consumption profile pattern to be mostly be shifted towards the afternoon.

It is also important to note the relatively sudden onset in the usage pattern around $04 \mathrm{~h} 00$ to $05 \mathrm{~h} 00$, showing that these households are early risers (typical of rural areas). In general, it is logical that the hot water consumption onset peak will start around the time when people rise. The rest of the daily hot water draw-off pattern would depend on the daily routine of that particular homestead, and be influenced by user occupancy. The average per capita hot water consumption (litres per person per day) for low-density homesteads is also influenced by seasonal effects such as average temperature changes (Meyer \& Tshimankinda, 1997). The example presented in Figure 9(a) shows a South African hot water consumption profile (with the

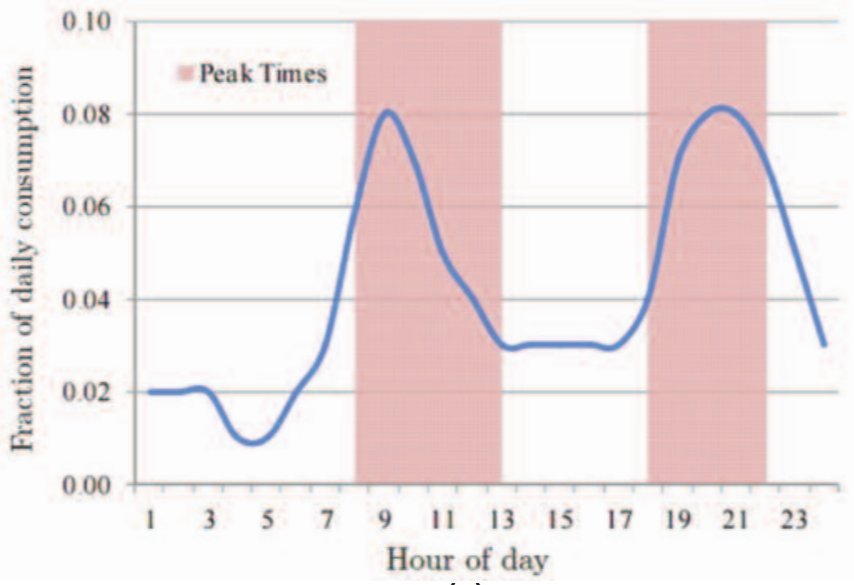

(a)

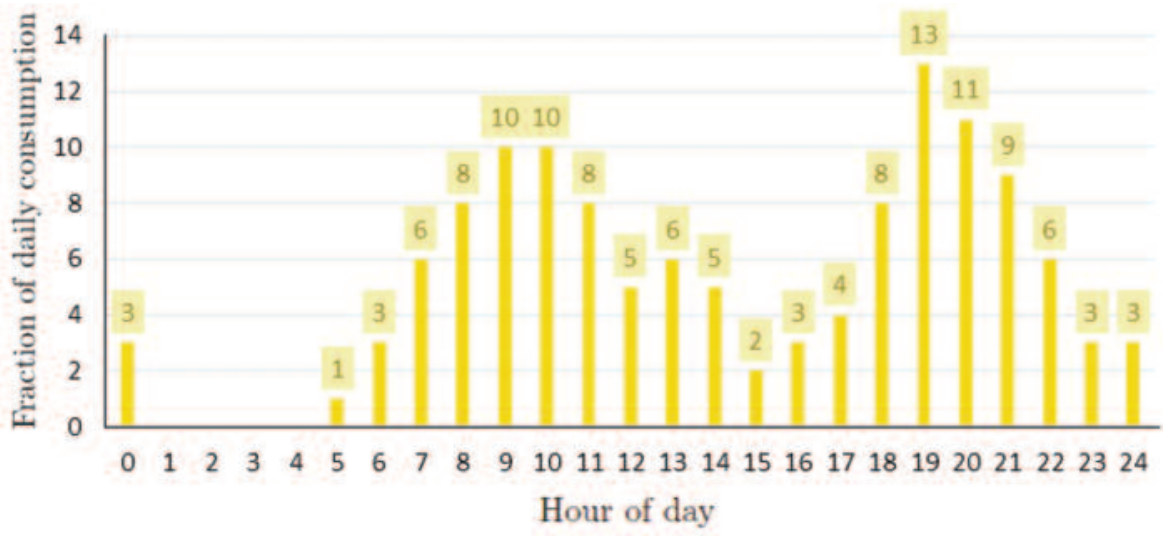

(b)

Figure 9: Hot water consumption profile for (a) a South African household, and (b) an Indian household (Meyer \& Tshimankinda, 1997; Sameti et al., 2014). 
peak band marked in the maroon bars), and Figure 9(b) shows a so-called Rand profile for the fraction of daily hot water energy consumption. This Rand profile is an archetypal profile pattern profile shape used to represent daily hot water consumption (120 litres at a temperature of $50{ }^{\circ} \mathrm{C}$ ) for a family of four (Sameti et al., 2014). These profiles agree with the findings of Meyer shown in Figure 9.

The REEE 5/99 report on the Simulation and monitoring of solar powered electric water heating systems in Namibia used pre-installed digital data logging and flow rate recording equipment to report on hot water usage patterns in rural Namibia (EMCON, 2000). The report shows graphs of hot water consumption patterns measured at sites in Namibia, with plots of hot water draw-off patterns in terms of month-days, week-days and daily-hours measured in a variety of households. Figure 10 shows the hot water drawing pattern for an independently located low-income household of seven people (EMCON, 2000). The data was recorded with a digital data logger to show two important results. Figure 10(a) shows the household's typical hot water consumption for each day of the week, and Figure 10(b) shows the average hourly hot water consumption profile for the household in hour time steps.

This section concludes with a reference to the thermal energy requirements related to cooking in a rural African village. The micro-CHP system will be able to supplement some of the heat required for

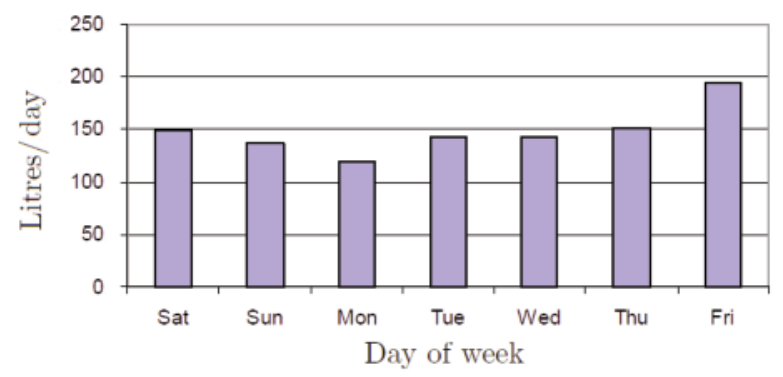

(a)

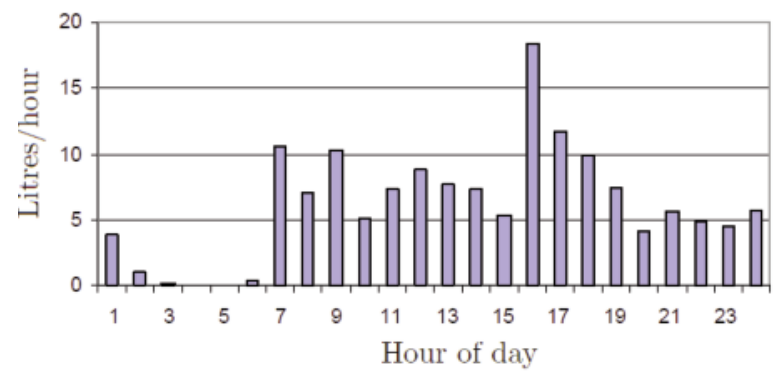

(b)

Figure 10: Recorded hot water draw-off patterns for a low-income homestead in Namibia, showing the average hot water drawoff pattern per week (a) and draw-off per day (b) (EMCON, 2000). cooking, which is why this thermal energy profile is considered to be important. In this regard, Figure 11 shows a digitised version of a daily cooking profile, indicating the electricity used for a recently electrified rural homestead in southern Africa (Cross and Gaunt, 2003).

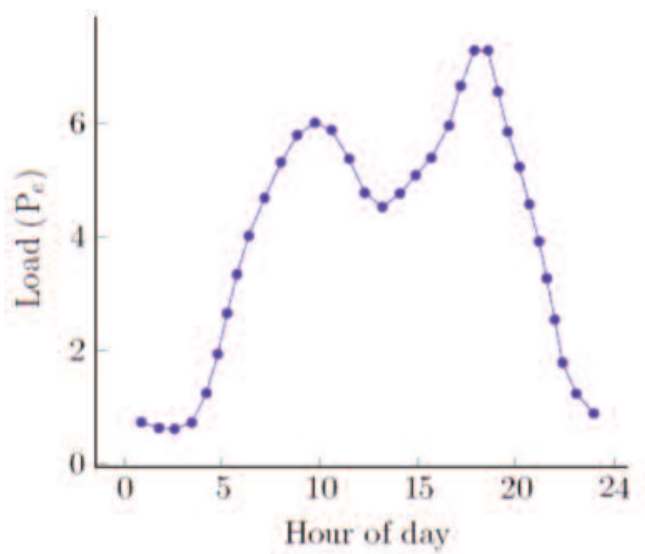

Figure 11: Daily cooking activity profile for rural house in South Africa (Cross \& Gaunt, 2003).

Although this paper will not discuss this profile in detail, it is valuable to note that the cooking profile is similar to the hot water usage profile. Once again, occupant behaviour may be related to the profile peaks and will vary between households. From the information presented in this part of the scoping exercise, one can more confidently define appropriate load requirements for rural African communities. The above exercise thus forms the basis for formulating a reference daily energy profile, in anticipation of a potential transition for the village towards a modern solar co-generation supply system.

\section{Consolidation of the load profiling results}

Load profiling and energy consumption analysis is central in energy usage planning and micro-CHP modelling analysis for isolated and remote rural areas. Realistic load profiles are required, and serve as a guideline for the supply system design, as well as the dynamic distribution viability on the demand side. This scoping exercise focused on the thermal (mainly hot water) and electrical load profiles. The results should be presented in a data format suitable for reading or import by thermodynamic and electrical multi-carrier microgrid technology platforms and smartgrid software simulation platforms. These computer modelling simulation tools typically use the terms 'Rows-per-day' or 'Single-column data' to describe the format used to save data. In the Rowsper-day format, daily load profile data is saved as 24-hour packets (i.e. date, time, $\mathrm{kWh}$ ) in a single row with the following day in the next row, etc. In the single column format, all the data can be saved in a single column. In these formats, every line record in the dataset may contain several energy 
parameter fields, separated by a comma, semicolon, tab or blank characters.

The focus of this study is on finding load profile shapes for hot water and electricity consumption that are typical for rural African households. This means that less emphasis is placed on the actual quantity of energy used ( $\mathrm{kW}$ or litres of hot water), but rather on the amount used per time step relative to other times of the day. The aim is to provide a scientific base for evaluating and comparing technology options and control automation options based on realistic load profile patterns for African villages. At the same time, an understanding is required of the operational requirements in an offgrid village with no previous access to electricity. This will assist in emulating a profile that is realistically comparable to experiences and trends observed in the load patterns from recently electrified rural homes. This, in turn, can be used in computer models and simulation experiments aimed at rural African customised system design. The previous section described the context and circumstances around rural African village energy consumption. Following an energy load profile scoping exercise, the background from available literature allows one to experiment with realistic thermal power consumption patterns in such locations (Tinarwo, 2008; Sprei, 2002; Meyer, 2000; Muya, 1996). The remainder of the discussion offers basic archetypal energy reference shapes for rural heat and power load profiles aimed at micro-CHP research for rural Africa.

\subsection{Rural African village electricity use profile pattern: Scoping}

From the scoping exercise, a load profile that defines a realistic reference consumption pattern for a rural African homestead needs to be selected. The key aspect in defining the archetype is the one that relates to the time of energy consumption over a 24 hour time interval.

In this paper, Section 2 presented information on the patterns of rural African electricity usage, with data and plots offering various options from which to select a potential candidate load profile reference pattern for use as electrical load pattern for remote isolated rural village homesteads in Africa. The shape of the electrical load profile for rural Western Australia (Figure 4(b)) may seem particularly familiar, as it has informally become a standard or benchmark reference in many studies that require a rural energy load profile and is often used as an exemplary load profile in computer modelling studies (Ibrahim \& Ilinca, 2012; Nayar, 2014). It is similar to the profiles measured by Tinarwo (2008) in Figure 3(a) and Sprei (2002) in Figure 3(b), which are other attractive candidates, both correlating well with the experimental energy load profile models developed as representative models of ener- gy consumption in rural African (Casillas \& Kammen, 2012; Yumoto, 2011; Ohijeagbon \& Ajayi, 2014; Kenneth and Tarilanyo, 2013). Of all the load profile shapes observed in this scoping exercise, the model in Figure 3(b) was found to be particularly valuable. This profile represents the rural African village context in a realistic way. The shape also correlates fairly well with rural profiles in other developing countries (Figure 4), as well as with African village load profile models generally used in computer simulation models (Figure 5). Since the Sprei (2002) dataset was measured with a high time-resolution, the load data should be smoothed to be comparable to hour-based resolution load profiles typically used in computer simulation models. For this reason, an interpolation algorithm was used on the measured dataset of Sprei to provide smoother average hourly energy usage samples. The resulting archetypal reference load profile is presented in Figure 12.

By using inverse algorithmic curve fitting techniques, one can further approximate this reference rural power load profile in terms of a mathematical expression. The formula given in Equation 1 offers one such approximation for the load $\mathrm{P}_{e}$ profile depicted in Figure 12, representing the electrical power consumption (kW) for a typical rural village demand load as a function of time.

$$
P_{e}={ }_{e}[\sin (0.3409-\sin (0.68039 t)-0.16801 t)]
$$

An important aspect in defining a reference archetype energy profile for a rural African homestead or village is to define the amplitude scale for the hourly load curve. This scale may represent the average daily level of the energy consumption, or the hourly power $\mathrm{kW}$ requirement for the household or rural village. From a rural African reference load profile perspective, one can correlate this requirement with government regulations, with IEA local load estimates, or alternatively to conduct a load synthesis analysis to determine the integrated scaled village load profile amplitudes (IEA, 2014, Prieto-Araujo et al., 2015).

From Table 3, it was noted that the monthly energy consumption level for a rural household not cooking with electricity is around $150 \mathrm{kWh}$, while the energy consumption for electricity cooking households averaged around $210 \mathrm{kWh}$ per household (Lloyd \& Cowan, 2004). An average monthly energy consumption level of $150 \mathrm{kWh}$ per month per rural household equates to approximately $0.484 \mathrm{kWh}$ per household per day. This estimated average daily electricity load would thus spread out over the 24-hour time period in accordance with the proposed archetypal hourly rural load profile shape in Figure 12. This would give the correct amplitude scaling of the curve.

When the village size changes, load scaling must 
further be used. In this way one can vary load profile magnitude as a function of village size (number of clustered homesteads grouped in a small rural village, connected to the same local microgrid distribution line). This means that the same geometric shape for the reference archetype energy profile in Figure 12 would be used to represent any village size by scaling the amplitude based on the number of houses. Figure 13 offers the final proposed and digitised hourly load time-series graph for a rural village settlement suitable for microgrid control intelligence analysis and experimentation. This digitised generic hourly scaled computer modelling dataset version of the proposed hourly rural village energy consumption profile is presented in an hourly format suitable for use in energy systems analysis and computer simulation platforms (i.e. TRNSYS, Homer, EnergyPlus, EnergyPlan, ReEds, REopt), as well as transactive financial and eco- nomic analysis packages (i.e. SAM, CREST, Community Solar Scenario).

\subsection{Rural African hot water profile pattern: \\ Scoping}

In terms of hot water consumption in a rural African energisation context, micro-CHP computer simulation evaluation experiments further require information about hot water usage in a rural African village. A valuable option is to learn from solar hot water draw-off patterns measured at flat-plate and evacuated tube solar hot water systems at remote locations. In general, domestic hot water patterns are driven by water use for household activities such as house cleaning, washing dishes, washing laundry, bathing and cooking. At the same time, this domestic hot water typically needs to be heated in a hot water heater and stored at around $55^{\circ} \mathrm{C}$, and then applied at a blended outlet temperature of

$\rightarrow-$ Hourly electricity load profile

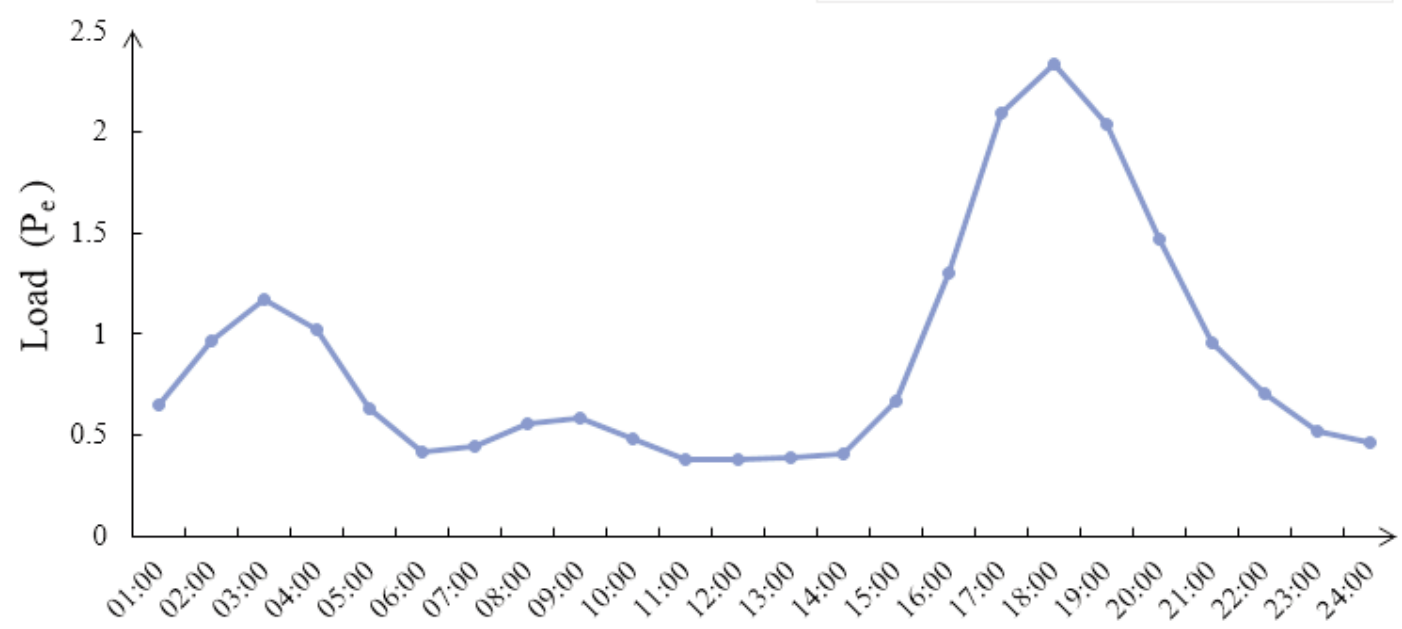

Hour of day

Figure 12: Potential rural electrical energy load profile reference shape for micro-CHP computer modelling and simulation experimentation.

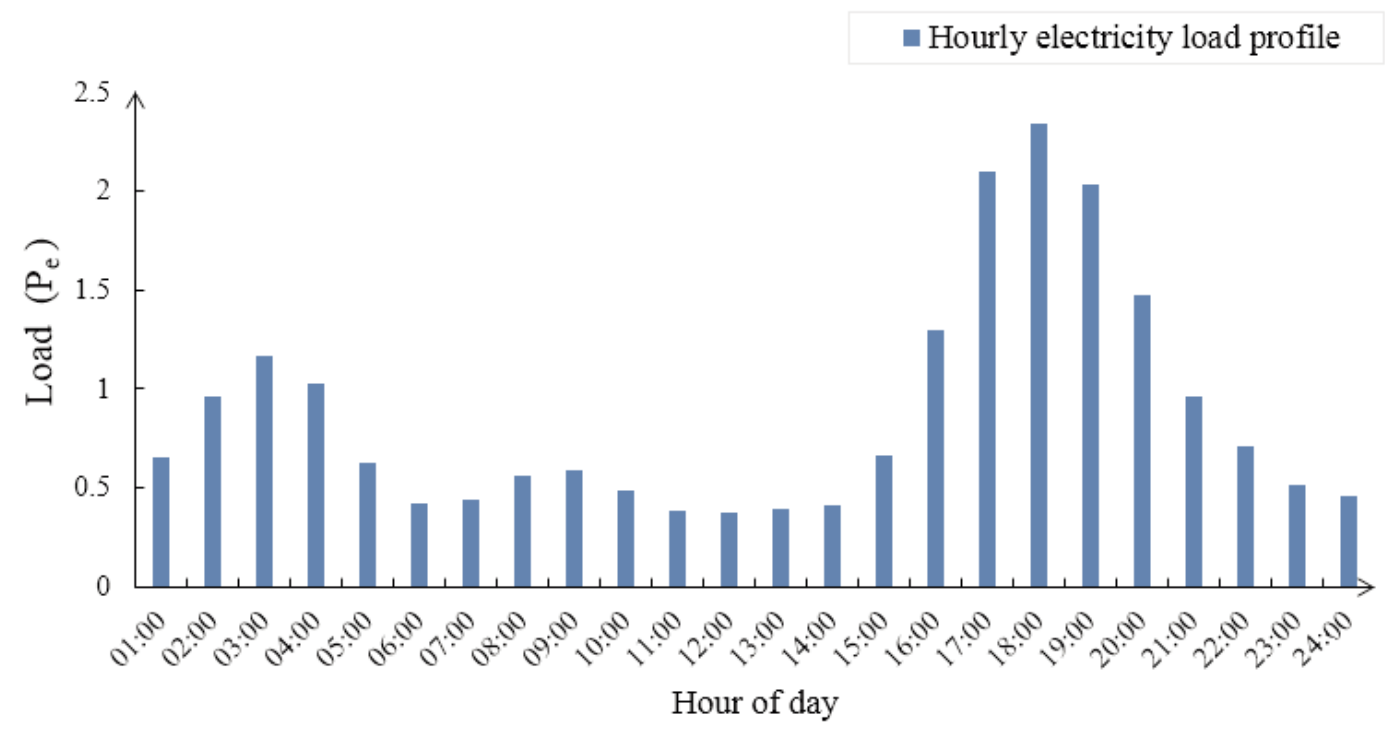

Figure 13: Reference hourly electrical energy load profile for rural African village suitable for microCHP computer modelling and simulation experimentation. 
around $40-45^{\circ} \mathrm{C}$ (Agama, 2002).

In the case of the first Namibian low-income household (Figure 10), seven people occupied the dwelling. The average measured daily hot water consumption per day was $14.4 \pm 4.8 \mathrm{l} /$ person, while a second low-income household with two inhabitants showed an average daily consumption of $23.7 \pm 5.8 \mathrm{l} /$ person (EMCON, 2000). The daily hot water consumption of rural African villages without access to municipal water is typically lower than the numbers found in this study (Meyer, 2000). While the exact amount of hot water used in each case may be different, the usage pattern in both of these studies follow the same trend.

Figure 8 shows the chosen geometric shape for hot water draw-off patterns which is based on extensive research by Muya (1996) and Meyer (2000) and should serve as the guideline in profilebased central domestic hot water distribution. Figure 14 represents the digitised computer modelling version of the proposed hourly hot water draw-off profile in a format suitable for use in computer software simulation and thermodynamic analysis platforms. This hourly time series hot water draw-off profile dataset can also be used to help validate and compare mathematical and computer simulation models for storage and control automation solutions in micro-CHP models.

The above load profiling and energy/hot water consumption analysis is central in the energy usage planning and micro-CHP modelling analysis for isolated and remote rural areas. The above section offers realistic load profiles in format suitable for computer simulation platforms. These profiles can now be used as archetype rural consumption reference shapes in solar microgrids and solar micro$\mathrm{CHP}$ system simulation experiments. It will in future also be helpful in comparing embedded off-grid dis- tribution management system control schemes and stand-alone distributed energy resource management system approaches in micro-CHP microgrid simulation experiments.

\section{Conclusions}

A community solar micro-CHP system generates energy from variable renewable energy sources. In such shared community energy systems, special consideration should be given to a control automation and energy management solution. Such a solution should be capable of energy conservation as well as energy supply and demand-balancing in scalable community microgrid configurations. To develop and evaluate suitable computer-guided control automation and storage solutions for digital micro-CHP system models in isolated rural microgrid applications, reference energy consumption profiles for the use (or potential use) of thermal and electrical energy usage is required. Even with the availability of Big Data and Smart metering, it is still proving to be difficult to find thermal and electrical energy profile shapes for a rural African village. A scoping exercise was subsequently performed to investigate how literature data can be used as means to define universal load profile shapes for a remote and isolated rural African context (Cross \& Gaunt, 2003; Heunis \& Dekenah, 2014; Meyer, 2000; Muya, 1996; OpenEI, 2015; Tinarwo, 2009; Sprei, 2002).

The results from the scoping exercise showed that the thermal and electrical profiles for domestic rural energy had certain characteristic features. The most important is the two peaks that have been extensively discussed. The scoping exercise showed that the peaks in the electrical and thermal loads coincided with the patterns of user activity, being present in the early morning and in the evening, with the latter always being more prominent. In

\section{n Hourly hot water draw}

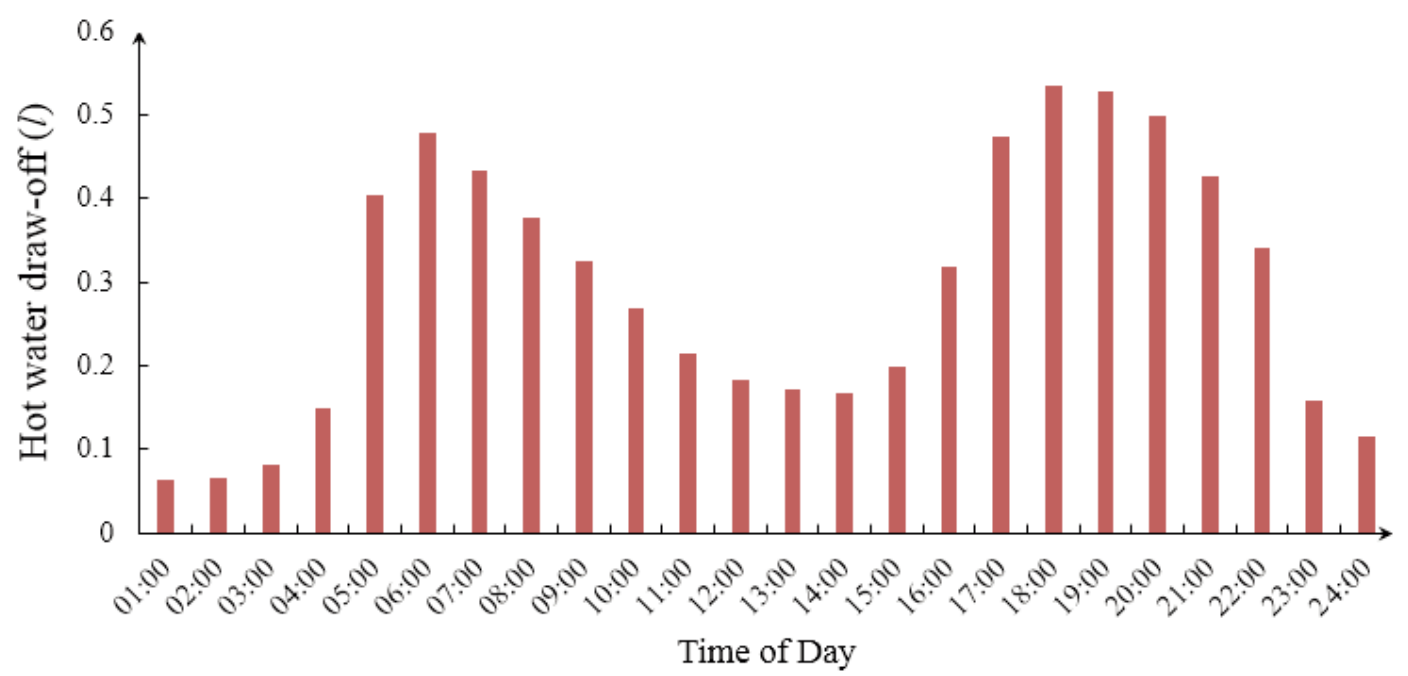

Figure 14: Proposed characteristic rural domestic hot water profile archetype reference shape for micro-CHP computer modelling and simulation experimentation 
some cases, a peak around noon could be seen and was mostly associated with agricultural communities.

From the scoping exercise, hot water usage by rural households is better understood. There is much more consistency in the data, which is different from electricity usage in rural households where patterns fluctuate greatly between studies. This means that even though the time of electricity consumption is known, it is difficult to know how much generation the system needs to be designed for. The scoping profile can also serve as baseline load in the development of a software tool to formulate and predict load profiles in multi-carrier microgrids for off-grid rural areas.

The outcome of the scoping exercise offers digitised computer model ready hourly electricity and hourly hot water draw-off profiles in a format suitable for use in dynamic microgrid analysis and computer software for energy simulation platforms (i.e. TrnSys, Homer Energy, EnergyPLAN, EnergyPlus, ReEds, RetScreen, Leap, and OSeMOSYS). These hourly time series electricity usage and hot water draw-off profile datasets can now be used to help validate and compare mathematical and computer simulation models for storage and control automation solutions in micro-CHP models. It will also be useful in techno-economic analyses for integrated or isolated district community energy systems. Disaggregated load profiles (radio, TV, cellphone charger, lights, security system) derived from the above load profiles will further help to develop demand response, demand management, responsive load curtailment and dynamic load control systems, to account for renewable supply variability in distributed energy resources within sustainable rural development systems.

\section{Acknowledgments}

The authors thank the South African Department of Science and Technology, the National Research Foundation for funding this research work.

\section{References}

Africa, L., Blore, M., Dwight, R., Reichhardt, C., Retief, D., Mpando, T., 2008. Domestic energy use of low income households in Grahamstown East. State of the Environment Report (SoER) for Grahamstown, Eastern Cape, 1-29.

Agama, 2002. Sustainable Energy Services, Lynedoch Eco-Village. AGAMA Energy (Pty) Ltd P O Box 606, Constantia, 7848, South Africa, 1-28.

Aron, J., Eberhard, A., Gandar, M., 1991. Fuelwood deficits in rural South Africa. Biomass and Bioenergy 1 (2); 89-98.

Barbieri, E. S., Spina, P. R., Venturini, M., 2012. Analysis of innovative micro-CHP systems to meet household energy demands. Applied Energy 97: 723-733.

Bokanga, G. M., Kahn, M. T. E., 2014. Design of a low voltage DC microgrid system for rural electrification in South Africa 25 (2), 9-14.

Casillas, C. E., Kammen, D. M., 2012. The challenge of making reliable carbon abatement estimates: The case of diesel microgrids. S.A.P.I.EN.S. Surveys and Perspectives Integrating Environment and Society Journal 5 (1).

Cho, H., Eksioglu, S. D., Luck, R., Chamra, L. M., 2008. Operation of a CCHP system using an optimal energy dispatch algorithm. ASME 2008 2nd International Conference on Energy Sustainability collocated with the Heat Transfer, Fluids Engineering; 1-8.

Cho, H., Luck, R., Chamra, L. M., 2007. Dynamic simulation of a Micro-CHP facility: A case study. ASME 2007 Energy Sustainability Conference, Long Beach, California, USA; 247-254.

Cross, N., and Gaunt, C., 2003. Application of rural residential hourly load curves in energy modelling. IEEE Conference: Power Tech Conference Proceedings, 2003 IEEE Bologna; 1-4.

Dagbjartsson, G., Gaunt, C., Zomers, A., 2007. Rural electrification: A scoping report. Cigre Working Group C6-13 Rural Electrification Workshop 1; 124.

Damte, A., Koch, S. F., Mekonnen, A., 2012. Coping with Fuelwood Scarcity. Household Responses in Rural Ethiopia. Environment for Development. Disucssion Paper Series 12-01 (January), 1-34.

Deloitte, 2011. Advanced metering infrastructure customer impacts study. Department of Primary Industries, Victoria, Australia, Final report: Volume 1 and 2 (1), 1-89.

Department of Minerals and Energy, 2003. Electricity basic support services tariff (Free basic electricity) policy. Pretoria: Department of Minerals and Energy, South Africa (DME), 1-5.

EMCON, 2000. Simulation and monitoring of solar and electric water heating systems. REEE 5/99, EMCON Consulting Engineers for Ministry of Mines and Energy Private Bag 13297, Windhoek, Namibia, 1116.

Fall, N., Giles, L., Marchionini, B., Skolnik, E. G., 2007. Remote area power supply (RAPS) load and resource profiles: A study for the DOE energy storage program. SAND REPORT SAND2007-4268 Unlimited Release Printed July 2007 (July), 47.

Fogarty, A., 2015. African Kaleidoscope Safari, Code (OV08) A 12 day tour. Overnight Tours 1 (1), 1-2. [online] http://mobi.alantours.co.za/mobi_listings/overnight_to urs (accessed 1 Sept 2015).

Harris, A., Kilfoil, M., Uken, E., 2008. Options for residential hot water heating. Energy Technology Unit, Cape Peninsula University of Technology, Cape Town, South Africa, 1-8.

Heunis, S., Dekenah, M., 2014. A load profile prediction model for residential consumers in South Africa. Proceedings of the 22nd Conference on the Domestic Use of Energy, DUE 2014, 3-8. 
Ho, C. K., 2008. Software and codes for analysis of concentrating solar power technologies. Sandia National Laboratories, Report SAND2008-8053 (December), 1-35.

Hussein Ibrahim, H. and Ilinca, A., 2012. Contribution of the Compressed Air Energy Storage in the Reduction of GHG - Case Study: Application on the Remote Area Power Supply System, Air Pollution - A Comprehensive Perspective, Dr. Budi Haryanto (Ed.), InTech, DOI: 10.5772/50131.

International Energy Agency, 2014. Africa Energy Outlook. A focus on the energy prospects in subSaharan Africa. World Energy Outlook Special Report, International Energy Agency Publication, 1237.

iShack, 2013. The iShack: A business model for incrementally upgrading informal settlements. Sustainability Institute, Stellenbosch University (April), Stellenbosch, South Africa. 2011-2014.

Kenneth, A. P., Tarilanyo, A. J., 2013. Developing sustainable power supply for rural communities in Akassa of Bayelsa state using photovoltaic system and battery. Research Journal of Applied Sciences, Engineering and Technology 6 (4), 545-550.

Ketjoy, N., 2005. Photovoltaic hybrid systems for rural electrification in the Mekong countries. University of Kessel, Library, 1-135.

Kruger, J. L., 2007. Towards an appropriate framework for South African rural renewable energy provision. MPhil dissertation, Stellenbosch University, Stellenbosch, South Africa. (December), 1-180.

Lloyd, P., 2014. The energy profile of a low-income urban community. Domestic Use of Energy Conference, 29 March 2 April, 2014, Cape Town, South Africa 25 (3), 80-85.

Lloyd, P., Cowan, B., 2004. Improving access to electricity: Lessons from Khayelitsha. Energy Research Centre, University of Cape Town, South Africa, 1-6.

Lund, H., 2015. Renewable energy systems: A smart energy systems approach to the choice and modeling of $100 \%$ renewable solutions. Academic Press, 225 Wyman Street, Waltham, MA, USA, ISBN: 9780124104235: 1-384.

Makungwa, S. D., Epulani, F., Woodhouse, I. H., 2013. Fuelwood supply: A missed essential component in a food security equation. Journal of Food Security 1 (2); 49-51.

Masekoameng, K. E., 2005. Household energy needs and utilization patterns in the Giyani rural communities of Limpopo Province, South Africa. Journal of Energy in Southern Africa 16 (3), 4-9.

Meyer, J. P., 2000. A review of domestic hot-water consumption in South Africa. $R$ \& D Journal 16; 55-61.

Meyer, J. P., Tshimankinda, M., 1997. Hot water consumption by developing communities in South African traditional houses. International Journal of Energy Research 21 (12); 667-673.

Mulaudzi, S., Qase, N., 2008. New and renewable energy: Mini-grid hybrid viability and replication potential: The Hluleka and Lucingweni pilot projects. Department of Minerals and Energy of South Africa, 1-299. Pretoria, South Africa.

Muya, T., 1996. Hot water consumption in South Africa.
Phd dissertation, Rand Afrikaans University (now University of Johannesburg), Johannesburg, South Africa.

Nayar, C., 2014. Energy security in small islands and remote communities through innovative micro-grid systems. Remote Area Power Supply Conference, Regen Power Sustainable Power Solutions (3), 1-65.

Ohijeagbon, O. D. and Ajayi, O. O., 2014. Potential and economic viability of standalone hybrid systems for a rural community of Sokoto, North-west Nigeria. Frontiers in Energy 8 (2); 145-159.

OpenEI, 2015. Commercial and residential hourly load profiles for all TMY3 locations in the United States. Available from http://en.openei.org/doeopendata/dataset/commercial-and-residential-hourlyload-profiles-for-all-tmy3-locations-in-the-unitedstates [Accessed 25 Sept 2015].

Palmer, C., MacGregor, J., 2008. Fuelwood scarcity, energy substitution and rural livelihoods in Namibia. Proceedings of the German Development Economics Conference, Zurich (32), 1-29.

Prieto-Araujo, E., Olivella-Rosell, P., Cheah-Mane, M., Villafafila-Robles, R., Gomis-Bellmunt, O., 2015. Renewable energy emulation concepts for microgrids. Renewable and Sustainable Energy Reviews, Elsevier 50; 325-345.

Prinsloo, G. J. and Dobson, R. T., 2015. Combined solar heat and power with microgrid storage and layered smartgrid control toward supplying off-grid rural villages. Energy Science \& Engineering 3 (2): 135-144.

Reddy, Y., 2008. An exploration of household energy use patterns among grid electrified households in low-income rural and peri-urban communities in South Africa. PhD thesis, University of Cape Town, Cape Town, South Africa.

Sameti, M., Kasaeian, A., Mohammadi, S. S. and Sharifi, N., 2014. Thermal performance analysis of a fully mixed solar storage tank in a ZEB hot water system. Sustainable Energy 2 (2): 52-56.

Scheurlen, E., 2015. Time allocation to energy resource collection in rural Ethiopia gender-disaggregated household responses to changes in firewood availability. IFPRI Discussion Paper 01419, Environment and Production Technology Division, International food Policy Research Institute, 1-48.

Shackleton, C., Gambiza, J. and Jones, R., 2007. Household fuelwood use in small electrified towns of the Makana District, Eastern Cape, South Africa. Journal of Energy in Southern Africa 18 (3): 4-10.

Shilts, E. and Fischer, B., 2014. We plotted 812,000 energy usage curves on top of each other, this is the powerful insight we discovered. OPower Labs, Loadcurve-archetypes. Available online: https://blog.opower.com/2014/10/load-curvearchetypes/ [Accessed 20 Sept 2015].

Sprei, F., 2002. Characterization of power system loads in rural Uganda. Masters thesis, Lund University of Technology, Lund, Sweden.

Susanto, J., 2012. Limits of grid extension in the Lao PDR: A financial perspective. Journal of Humanitarian Engineering 1 (1): 27-38.

Tinarwo, D., 2009. Design of village power and micro- 
grids for rural areas of Zimbabwe with specific attention to voltage regulation on low voltage meshed distribution grids. Kassel University Press, Kassel, Germany.

United Nations Development Programme, 2011.

Sustainability and equity: A better future for all. Human Development Report, United Nations Development Programme, New York. 1-58.

Verma, A., Biswas, S. and Ahmad, S. Y., 2015. Technofinancial analysis of energy access through hybrid system with solar PV under the various rural community models for State of Uttarakhand, India. Smart Grid and Renewable Energy 6 (April): 75-94.

World Health Organisation, 2010. Households using solid fuels as the primary cooking fuel, by WHO region. WHO Global Health Observatory Repository, World Health Organisation, Geneva, Switzerland, 110.

Yumoto, N., 2011. Sustainability conditions for PV hybrid systems: Environmental considerations. Energy and Environment Institute, IEA PVPS Task 11 Report IEA-PVPS T11-03:2011, 1-28. 